\title{
Application of the Modigliani-Miller Theory, Modified for the Case of Advance Payments of Tax on Profit, in Rating Methodologies
}

\author{
P.N. Brusov ${ }^{1, *}$, T.V. Filatova ${ }^{2}$, N.P. Orekhova ${ }^{3}$, V.L. Kulik ${ }^{4}$, S.-I. Chang ${ }^{5}$ and Y.C.G. Lin ${ }^{5}$ \\ ${ }^{1}$ Department of Mathematics, Financial University under the Government of Russian Federation, Moscow, \\ Russia \\ ${ }^{2}$ Department of financial and investment management, Financial University under the Government of Russian \\ Federation. Moscow, Russia \\ ${ }^{3}$ High Business school, Southern Federal University, Rostov-on-Don. Russia \\ ${ }^{4}$ Deutsche Bank Ltd. Moscow, Russia \\ ${ }^{5}$ College of Management, National Chung Cheng University, Taiwan
}

\begin{abstract}
During a couple years we have suggested a new approach to rating methodology of non-financial issuers, as well for project rating. The key factors of a new approach are: 1) The adequate use of discounting of financial flows virtually not used in existing rating methodologies, 2) The incorporation of rating parameters (financial "ratios") into the modern theory of capital structure (Brusov-Filatova-Orekhova (BFO) theory) and into its perpetuity limit.

Recently we have generalized the Modigliani and Miller theory for a more realistic method of payments of tax on profit: for the case of advance payments of tax on profit, which is widely used in practice. Modigliani - Miller theory accounts these tax payments as annuity-immediate, while in practice these payments are making in advance and thus should be accounting as annuity-due. We have shown that this generalization leads to some important consequences, which change seriously all the main statements by Modigliani and Miller.

In current paper we use the modified Modigliani - Miller theory (MMM theory) and apply it for rating methodologies needs. A serious modification of MMM theory in order to use it in rating procedure has been required. The financial "ratios" were incorporated into MMM theory. The dependence of the weighted average cost of capital (WACC), which plays the role of discount rate, on coverage and leverage ratios is analyzed.

Obtained results make possible to use the power of this theory in the rating and create a new base for rating methodologies.
\end{abstract}

Keywords: Modified Modigliani-Miller theory, Brusov-Filatova-Orekhova (BFO) theory, advance payments of tax on profit, rating methodologies.

\section{INTRODUCTION}

In our previous papers (Brusov et al. 2018; 2019; 2020b) we have applied the theory of Nobel Prize winners Modigliani and Miller, which is the perpetuity limit of the general theory of capital cost and capital structure - Brusov-Filatova-Orekhova (BFO) theory (Brusov et al. 2011; 2014; 2015; 2018) for rating needs. It has become a very important step in developed of a qualitatively new rating methodology.

Recently we have generalized the Modigliani and Miller theory (Modigliani and Miller, 1958; 1963; 1966) for a more realistic method of tax on profit payments: for the case of advance payments of tax on profit, which is widely used in practice (Brusov et al. 2020). Modigliani - Miller theory accounts these tax payments as annuity-immediate, while in practice these

*Address correspondence to this author at the Department of Mathematics, Financial University under the Government of Russian Federation, Moscow, Russia; Tel: +7-906-0675975; Fax: +7-906-0675975;

E-mail: pnb1983@yahoo.com payments are making in advance and thus should be accounting as annuity-due.

We have shown that this generalization leads to some important consequencies, which change seriously all the main statements by Modigliani and Miller (Modigliani and Miller, 1958; 1963; 1966). These consequencies are as following: WACC starts depend on debt cost kd, WACC turns out to be lower than in case of classical Modigliani-Miller theory and thus company capitalization becomes higher than in ordinary Modigliani-Miller theory.We show that equity dependence on leverage level $L$ is still linear, but the tilt angle with respect to $L-a x i s$ turns out to be smaller: this could lead to modification of the divident policy of the company.

In current paper we use modified Modigliani - Miller theory (MMM theory) and apply it for rating methodologies needs. A serious modification of MMM theory in order to use it in rating procedure has been required. The financial "ratios" (main rating parameters) 
were introduced into MMM theory. The necessity of an appropriate use of financial flows discounting in rating methodologies is discussed. The dependence of the weighted average cost of capital (WACC), which plays the role of discount rate, on coverage and leverage ratios is analyzed.

Obtained results make possible to use the power of this theory in the rating and create a new base for rating methodologies, by other words this allows develop a new approach to methodology of rating, requiring a serious modification of existing rating methodologies.

\section{MODIFIED MODIGLIANI-MILLER THEORY}

Let us shortly discuss some main points of Modified Modigliani-Miller theory (MMM) and its features, which are different from ones of "classical" Modigliani-Miller theory (Brusov et al., 2020a).

\section{Tax Shield}

To calculate tax shield TS in case of advance tax payments one should use annuity-due

$$
T S=k_{d} D t+\frac{k_{d} D t}{\left(1+k_{d}\right)}+\frac{k_{d} D t}{\left(1+k_{d}\right)^{2}}+\ldots=\frac{k_{d} D t}{\left(1-\left(1+k_{d}\right)^{-1}\right)}=D t\left(1+k_{d}\right)
$$

This expression is different from the case of classical Modigliani-Miller theory (which used annuityimmediate).

$$
T S=\frac{k_{d} D t}{\left(1+k_{d}\right)}+\frac{k_{d} D t}{\left(1+k_{d}\right)^{2}}+\ldots=\frac{k_{d} D t}{\left(1+k_{d}\right)\left(1-\left(1+k_{d}\right)^{-1}\right)}=D t
$$

Thus in the former case tax shield TS is bigger by multiplyer $\left(1+k_{d}\right)$. This is connected with the time value of money: money today is more expensive than money tomorrow due to the possibility of their alternative investment.

\section{The Weighted Average Cost of Capital, WACC}

For WACC in MMM theory we have the following formula:

$W A C C=k_{0}\left(1-w_{d} t\left(1+k_{d}\right)\right)$.

At $L \rightarrow \infty W A C C=k_{0}\left(1-t\left(1+k_{d}\right)\right)$.

This expression is different from the similar one in classical Modigliani-Miller theory
$W A C C=k_{0}\left(1-w_{d} t\right)$

At $L \rightarrow \infty \quad W A C C=k_{0}(1-t)$.

From these expressions it is seen that WACC decreases with $\mathrm{L}$, achieving lower value $W A C C=k_{0}\left(1-t\left(1+k_{d}\right)\right)$ at $L \rightarrow \infty$ in considering case comparing with classical Modigliani-Miller theory $W A C C=k_{0}(1-t)$.

This means also, that company capitalization becomes higher than in ordinary Modigliani-Miller theory.

Let us compair the dependence of the weighted average cost of capital, WACC, on leverage level in "classical" Modigliani-Miller theory (MM theory) and in modified Modigliani-Miller theory (MMM theory). Study of such dependence is very important, because, the

Table 1: Dependence of WACC on Leverage Level in "Classical" Modigliani-Miller Theory

\begin{tabular}{|c|c|c|c|}
\hline ko & $\mathbf{L}$ & $\mathbf{t}$ & WACC \\
\hline \hline 0.2 & 0 & 0.2 & 0.2000 \\
\hline 0.2 & 1 & 0.2 & 0.1800 \\
\hline 0.2 & 2 & 0.2 & 0.1733 \\
\hline 0.2 & 3 & 0.2 & 0.1700 \\
\hline 0.2 & 4 & 0.2 & 0.1680 \\
\hline 0.2 & 5 & 0.2 & 0.1667 \\
\hline 0.2 & 6 & 0.2 & 0.1657 \\
\hline 0.2 & 7 & 0.2 & 0.1650 \\
\hline 0.2 & 8 & 0.2 & 0.1644 \\
\hline 0.2 & 9 & 0.2 & 0.1640 \\
\hline 0.2 & 10 & 0.2 & 0.1636 \\
\hline
\end{tabular}

Table 2: Dependence of WACC on Leverage Level in Modified Modigliani-Miller Theory (MMM Theory) at $k d=0.18$

\begin{tabular}{|c|c|c|c|c|}
\hline ko & $\mathbf{L}$ & $\mathbf{t}$ & $\mathbf{k d}$ & WACC \\
\hline \hline 0.2 & 0 & 0.2 & 0.18 & 0.2000 \\
\hline 0.2 & 1 & 0.2 & 0.18 & 0.1764 \\
\hline 0.2 & 2 & 0.2 & 0.18 & 0.1685 \\
\hline 0.2 & 3 & 0.2 & 0.18 & 0.1646 \\
\hline 0.2 & 4 & 0.2 & 0.18 & 0.1622 \\
\hline 0.2 & 5 & 0.2 & 0.18 & 0.1607 \\
\hline 0.2 & 6 & 0.2 & 0.18 & 0.1595 \\
\hline 0.2 & 7 & 0.2 & 0.18 & 0.1587 \\
\hline 0.2 & 8 & 0.2 & 0.18 & 0.1580 \\
\hline 0.2 & 9 & 0.2 & 0.18 & 0.1575 \\
\hline 0.2 & 10 & 0.2 & 0.18 & 0.1571 \\
\hline
\end{tabular}


Table 3: Dependence of WACC on Leverage Level in Modified Modigliani-Miller Theory (MMM Theory) at $\mathbf{k d}=0.14$

\begin{tabular}{|c|c|c|c|c|}
\hline ko & $\mathbf{L}$ & $\mathbf{t}$ & $\mathbf{k d}$ & WACC \\
\hline \hline 0.2 & 0 & 0.2 & 0.14 & 0.2000 \\
\hline 0.2 & 1 & 0.2 & 0.14 & 0.1772 \\
\hline 0.2 & 2 & 0.2 & 0.14 & 0.1696 \\
\hline 0.2 & 3 & 0.2 & 0.14 & 0.1658 \\
\hline 0.2 & 4 & 0.2 & 0.14 & 0.1635 \\
\hline 0.2 & 5 & 0.2 & 0.14 & 0.1620 \\
\hline 0.2 & 6 & 0.2 & 0.14 & 0.1609 \\
\hline 0.2 & 7 & 0.2 & 0.14 & 0.1601 \\
\hline 0.2 & 8 & 0.2 & 0.14 & 0.1595 \\
\hline 0.2 & 9 & 0.2 & 0.14 & 0.1590 \\
\hline 0.2 & 10 & 0.2 & 0.14 & 0.1585 \\
\hline
\end{tabular}

weighted average cost of capital, WACC, plays the role of discount rate in operating financial flows discounting as well as of financial flows in rating methodologies. WACC's value determines as well the capitalization of the company $V=C F / W A C C$. We use Microsoft Excel for calculations.

From the Tables 1-4 and from Figure 1 it is seen that WACC in MMM theory turns out to be lower than in case of classical Modigliani-Miller theory and thus
Table 4: Dependence of WACC on Leverage Level in Modified Modigliani-Miller Theory Theory) at kd=0.1

\begin{tabular}{|c|c|c|c|c|}
\hline ko & $\mathbf{L}$ & $\mathbf{t}$ & $\mathbf{k d}$ & WACC \\
\hline \hline 0.2 & 0 & 0.2 & 0.1 & 0.2000 \\
\hline 0.2 & 1 & 0.2 & 0.1 & 0.1780 \\
\hline 0.2 & 2 & 0.2 & 0.1 & 0.1707 \\
\hline 0.2 & 3 & 0.2 & 0.1 & 0.1670 \\
\hline 0.2 & 4 & 0.2 & 0.1 & 0.1648 \\
\hline 0.2 & 5 & 0.2 & 0.1 & 0.1633 \\
\hline 0.2 & 6 & 0.2 & 0.1 & 0.1623 \\
\hline 0.2 & 7 & 0.2 & 0.1 & 0.1615 \\
\hline 0.2 & 8 & 0.2 & 0.1 & 0.1609 \\
\hline 0.2 & 9 & 0.2 & 0.1 & 0.1604 \\
\hline 0.2 & 10 & 0.2 & 0.1 & 0.1600 \\
\hline
\end{tabular}

company capitalization becomes higher than in ordinary Modigliani-Miller theory. It is seen, that WACC decreases with debt cost $k_{d}$.

In paper (Brusov et al. 2020a) we study as well the equity cost dependence on leverage level $L$ and show that it is still linear, but the tilt angle with respect to Laxis turns out to be smaller in MMM theory $\operatorname{tg} \alpha=\left(k_{0}-k_{d}\right) \cdot(1-t)-k_{0} k_{d} t$, than in classical ModiglianiMiller theory $\operatorname{tg} \alpha=\left(k_{0}-k_{d}\right) \cdot(1-t)$. This could lead to

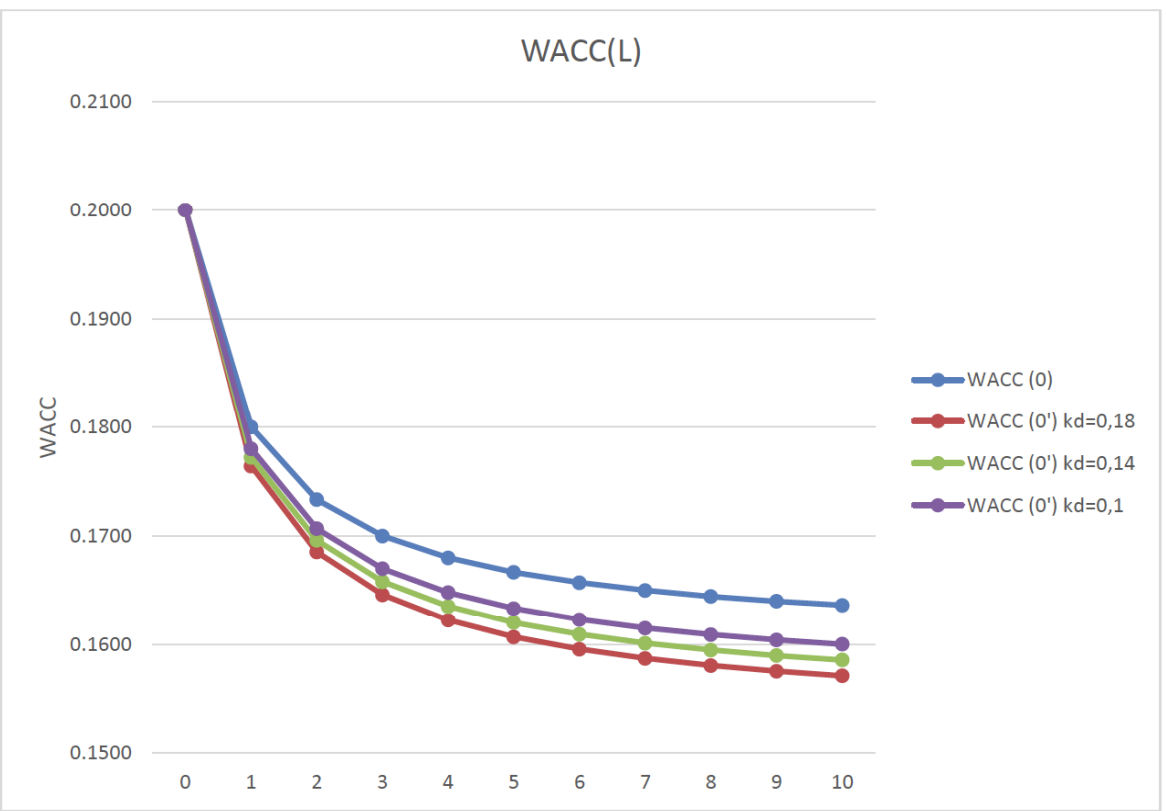

Figure 1: Dependence of WACC on leverage level L:

- in "classical" Modigliani-Miller theory (curve WACC(0)) and

- in modified Modigliani-Miller theory (MMM theory) at different values of debt cost: $k d=0.18 ; k d=0.14 ; k d=0.1 \quad(c u r v e s$ $\left.\operatorname{WACC}\left(0^{\prime}\right)\right)$. 
modification of the dividend policy of the company, because the equity cost represents itself economically sound value of dividends. Thus, company could decreases the value of dividends, which they should pay to shareholders.

Correct account of a method of tax on profit payments demonstrates that shortcomings of Modigliani - Miller theory are dipper, than everybody suggested: the underestimation of WACC really turns out to be bigger, as well as overestimation of the capitalization of the company. This means that systematic risks arising from the use of modified Modigliani - Miller theory (MMM theory) (which is more correct than "classical" one) in practice is higher than it was suggested by the "classical" version of this theory.

Because the advance payments of tax on profit is widely used in practice, modified Modigliani-Miller theory (MMM theory) should be use instead of classical version of this theory (MM theory). And below we apply the modified Modigliani-Miller theory for rating needs.

\section{APPLICATION OF MODIFIED OF MODIGLIANI- MILLER THEORY FOR RATING NEEDS}

Recently we have developed new modern methodologies for rating of non-financial issuers and of project ratings based on the use of the modern theory of cost and capital structure (BFO theory (Brusov Filatova - Orekhova theory) and of its perpetuity limit (Modigliani - Miller theory (MM theory), as well as modern investment models created by the authors (Brusov et al. 2018; 2019; 2020b).

In order to modify and improve existing rating methods to increase the objectivity and correctness of rating estimates, we critically analyzed the methodological and systemic shortcomings of the existing credit rating of non-financial issuers and project rating. The modern theory of capital cost and capital structure (BFO theory) for companies of arbitrary age and its perpetuity limit (Modigliani - Miller theory have been modified for rating needs. The incorporation of financial ratios used in the rating methodology was carried out both in the BFO theory and in its perpetuity limit: in the Modigliani - Miller theory. A fundamentally new approach to the rating methodology has been developed, which includes the adequate application of discounting, which is practically not used in existing rating methodologies, when discounting the financial flows; the use of rating parameters under discounting of financial flows and the correct determination of discount rates taking into account the financial ratios.
The proposed improvement of the rating methodology of existing rating systems will improve the accuracy of issued ratings and make them more objective. Using in rating methods of the modern theory of corporate finance, tools of well-developed theories of corporate finance (BFO theory and its perpetuity limits) allows us to move in the rating industry from the use of mainly qualitative rating methods to the use of mainly quantitative methods, which opens up new horizons in issuer rating and in determination methods their creditworthiness.

In current paper the modified Modigliani - Miller theory (MMM theory) have been applied for rating needs.

The financial "ratios", constitute a direct and inverse ratios of various generated cash flows to debt values and interest ones, play quite significant role in quantification of the creditworthiness of the issuers. The examples of such ratios are as following: DCF/Debt , FFO/Debt , CFO/Debt, FOCF/Debt , FFO/cash interest ,EBITDA/interest , Interests/EBITDA , Debt/EBITDA and some others.

We introduce these financial "ratios" into the modified perpetuity limit of modern theory of capital structure - BFO theory ((MMM theory), which is valid for companies of arbitrary age. This is quite important because allows use this theory as a powerful tools when discounting of financial flows using the correct discounting rate in rating.

This has required the modification of the perpetuity limit of the BFO theory - Modified Modigliani - Miller theory (MMM theory). The needs of modification is connected to the fact that used in financial management the concept of "leverage" as the ratio of debt value to the equity value substantially differs from the concept of "leverage" in the rating, where it is understood as ratio of the debt value to the generated cash flow values (income, profit, etc.).

Developed by us recently (Brusov et al. 2020a) modified Modigliani - Miller theory (MMM theory) with corporate taxes (Modigliani and Miller: 1966) shows that capitalization of financially dependent (leveraged) company, $V_{L}$, is equal to the capitalization of financially independent (unleveraged) company, $V_{0}$, increased by the size of the tax shield for perpetuity time, $D t\left(1+k_{d}\right)$,

$V_{L}=V_{0}+D t\left(1+k_{d}\right)$.

Substituting the expressions for both capitalizations, one has 


$$
\frac{C F}{W A C C}=\frac{C F}{k_{0}}+D t\left(1+k_{d}\right)
$$

Let us now introduce the parameters, using in ratings (ratios), into Modified Modigliani - Miller theory (MMM theory), which represents a perpetuity limit of modern theory of capital structure by Brusov-FilatovaOrekhova theory (BFO theory) (Brusov et al. 2015; 2018; 2019).

Two kind of financial ratios will be considered: coverage ratios and leverage ratios.

We will start from the coverage ratios.

\subsection{Coverage Ratios}

We will consider three kind of coverage ratios: coverage ratio of debt, coverage ratio of interest on the credit and coverage ratio of debt and interest on the credit.

\subsubsection{Coverage Ratios of Debt}

Let us consider first the coverage ratios of debt $i_{1}=C F / D$.

Dividing both parts of equation (7) by $D$ one gets

$$
\begin{aligned}
& \frac{i_{1}}{W A C C}=\frac{i_{1}}{k_{0}}+t\left(1+k_{d}\right) \\
& \frac{i_{1}}{W A C C}=\frac{i_{1}+k_{0} t\left(1+k_{d}\right)}{k_{0}} \\
& W A C C=\frac{i_{1} k_{0}}{i_{1}+t k_{0}\left(1+k_{d}\right)}
\end{aligned}
$$

The coverage ratio of debt $i_{1}=C F / D$ could be used for assessment of the following rating ratios: DCF/Debt , FFO/Debt, CFO/Debt, FOCF/Debt and some others. Formula (8) will be used to find a dependence $\operatorname{WACC}\left(i_{1}\right)$.

\subsubsection{Coverage Ratios of Interest on the Credit}

Consider now coverage ratio of interest on the credit $i_{2}=C F / k_{d} D$.

By use of the Modified Modigliani - Miller theory (MMM theory) for case with corporate taxes

$V_{L}=V_{0}+D t\left(1+k_{d}\right)$,

and dividing the both parts by $\mathrm{k}_{d} \mathrm{D}$, one could derive the expression for dependence $W A C C\left(i_{2}\right)$

$$
\frac{C F}{W A C C}=\frac{C F}{k_{0}}+D t\left(1+k_{d}\right)
$$

$\frac{i_{2}}{W A C C}=\frac{i_{2}}{k_{0}}+\frac{t\left(1+k_{d}\right)}{k_{d}}$

$W A C C=\frac{i_{2} k_{0} k_{d}}{i_{2} k_{d}+t k_{0}\left(1+k_{d}\right)}$

This ratio $\left(i_{2}\right)$ could be used for assessment of the following parameters, used in rating, FFO/cash interest, EBITDA/interest and some others. Formula (9) will be used to find a dependence $\operatorname{WACC}\left(i_{2}\right)$

\subsubsection{Coverage Ratios of Debt and Interest on the Credit}

Below we consider the coverage ratios of debt and interest on the credit simultaneously $i_{3}=\frac{C F}{D\left(1+k_{d}\right)}$. This is a new value, introduced by us here for the first time. Using the Modified Modigliani - Miller theory (MMM theory) for case with corporate taxes

$V_{L}=V_{0}+D t\left(1+k_{d}\right)$

and dividing the both parts by $(1+\mathrm{kd}) \mathrm{D}$ we get the dependence $\operatorname{WACC}\left(i_{3}\right)$

$\frac{C F}{W A C C}=\frac{C F}{k_{0}}+D t\left(1+k_{d}\right)$

$\frac{i_{3}}{W A C C}=\frac{i_{3}}{k_{0}}+\frac{t}{k_{d}}$

$W A C C=\frac{i_{3} k_{0} k_{d}}{i_{3} k_{d}+t k_{0}}$

This ratio $\left(i_{3}\right)$ could be used for assessment of the following rating ratios: $F F O /$ Debt + interest , EBITDA/Debt + interest and some others. Formula (10) will be used to find a dependence $W A C C\left(i_{3}\right)$.

\subsection{Dependence of WACC on Leverage Ratios of Debt in "Classical" Modigliani-Miller Theory (MM Theory) and Modified Modigliani-Miller Theory (MMM Theory)}

Below we study the dependences of WACC on leverage ratios of debt in "classical" Modigliani-Miller theory (MM theory) and modified Modigliani-Miller theory (MMM theory). We use Microsoft Excel, and the following parameters:

equity cost at $L=0 \mathrm{k} 0=0.2$; tax on profit rate $\mathrm{t}=0.2$; debt cost $k_{d}=0.1 ; 0.14 ; 0.18$; leverage ratios of debt $\mathrm{l}_{1}=0 ; 1 ; 2 ; 3 ; 4 ; 5 ; 6 ; 7 ; 8 ; 9 ; 10$. 
Table 5: Dependence of WACC on Coverage Ratios of Debt in "Classical" Modigliani-Miller Theory

\begin{tabular}{|c|c|c|c|}
\hline ko & $\mathbf{i}_{1}$ & $\mathbf{t}$ & WACC \\
\hline \hline 0.2 & 0 & 0.2 & 0.0000 \\
\hline 0.2 & 1 & 0.2 & 0.1923 \\
\hline 0.2 & 2 & 0.2 & 0.1961 \\
\hline 0.2 & 3 & 0.2 & 0.1974 \\
\hline 0.2 & 4 & 0.2 & 0.1980 \\
\hline 0.2 & 5 & 0.2 & 0.1984 \\
\hline 0.2 & 6 & 0.2 & 0.1987 \\
\hline 0.2 & 7 & 0.2 & 0.1989 \\
\hline 0.2 & 8 & 0.2 & 0.1990 \\
\hline 0.2 & 9 & 0.2 & 0.1991 \\
\hline 0.2 & 10 & 0.2 & 0.1992 \\
\hline
\end{tabular}

Table 6: Dependence of WACC on Coverage Ratios of Debt in Modified Modigliani-Miller Theory (MMM Theory) at $\mathrm{kd}=0.18$

\begin{tabular}{|c|c|c|c|c|}
\hline ko & i1 & $\mathbf{t}$ & kd & WACC \\
\hline \hline 0.2 & 0 & 0.2 & 0.18 & 0.0000 \\
\hline 0.2 & 1 & 0.2 & 0.18 & 0.1910 \\
\hline 0.2 & 2 & 0.2 & 0.18 & 0.1954 \\
\hline 0.2 & 3 & 0.2 & 0.18 & 0.1969 \\
\hline 0.2 & 4 & 0.2 & 0.18 & 0.1977 \\
\hline 0.2 & 5 & 0.2 & 0.18 & 0.1981 \\
\hline 0.2 & 6 & 0.2 & 0.18 & 0.1984 \\
\hline 0.2 & 7 & 0.2 & 0.18 & 0.1987 \\
\hline 0.2 & 8 & 0.2 & 0.18 & 0.1988 \\
\hline 0.2 & 9 & 0.2 & 0.18 & 0.1990 \\
\hline 0.2 & 10 & 0.2 & 0.18 & 0.1991 \\
\hline
\end{tabular}

Table 7: Dependence of WACC on Coverage Ratios of Debt in Modified Modigliani-Miller Theory (MMM Theory) at $\mathrm{kd}=0.14$

\begin{tabular}{|c|c|c|c|c|}
\hline ko & i1 & $\mathbf{t}$ & kd & WACc \\
\hline \hline 0.2 & 0 & 0.2 & 0.14 & 0.0000 \\
\hline 0.2 & 1 & 0.2 & 0.14 & 0.1913 \\
\hline 0.2 & 2 & 0.2 & 0.14 & 0.1955 \\
\hline 0.2 & 3 & 0.2 & 0.14 & 0.1970 \\
\hline 0.2 & 4 & 0.2 & 0.14 & 0.1977 \\
\hline 0.2 & 5 & 0.2 & 0.14 & 0.1982 \\
\hline 0.2 & 6 & 0.2 & 0.14 & 0.1985 \\
\hline 0.2 & 7 & 0.2 & 0.14 & 0.1987 \\
\hline 0.2 & 8 & 0.2 & 0.14 & 0.1989 \\
\hline 0.2 & 9 & 0.2 & 0.14 & 0.1990 \\
\hline 0.2 & 10 & 0.2 & 0.14 & 0.1991 \\
\hline
\end{tabular}

Table 8: Dependence of WACC on Coverage Ratios of Debt in Modified Modigliani-Miller Theory (MMM Theory) at $\mathbf{k d = 0 . 1}$

\begin{tabular}{|c|c|c|c|c|}
\hline ko & i1 & $\mathbf{t}$ & kd & WACC \\
\hline \hline 0.2 & 0 & 0.2 & 0.1 & 0.0000 \\
\hline 0.2 & 1 & 0.2 & 0.1 & 0.1916 \\
\hline 0.2 & 2 & 0.2 & 0.1 & 0.1957 \\
\hline 0.2 & 3 & 0.2 & 0.1 & 0.1971 \\
\hline 0.2 & 4 & 0.2 & 0.1 & 0.1978 \\
\hline 0.2 & 5 & 0.2 & 0.1 & 0.1983 \\
\hline 0.2 & 6 & 0.2 & 0.1 & 0.1985 \\
\hline 0.2 & 7 & 0.2 & 0.1 & 0.1988 \\
\hline 0.2 & 8 & 0.2 & 0.1 & 0.1989 \\
\hline 0.2 & 9 & 0.2 & 0.1 & 0.1990 \\
\hline 0.2 & 10 & 0.2 & 0.1 & 0.1991 \\
\hline
\end{tabular}

Let us analyze the dependence of company's weighted average cost of capital (WACC) on the coverage ratios on debt $i_{1}$. It is seen from Figure 2 that the weighted average cost of capital, WACC, increases with coverage ratio of debt for both versions of Modigliani-Miller theory: for "classical" ModiglianiMiller theory (MM theory) as well as for modified Modigliani-Miller theory (MMM theory). WACC increases very rapidly at $L$ increases from $L=0$ to $L=1$ and then comes to saturation very fast (after $L=3$ WACC changes very weak. At saturation WACC reaches the value $k_{0}$ (equity cost at zero leverage level). This means that for high values of $i_{j}$ one can choose $k_{0}$ as a discount rate with a good accuracy. Thus the role of parameter $k_{0}$ increases drastically. The method of determination of parameter $k_{0}$ has been developed by Anastasiya Brusova (Brusova, 2011). So, parameter $k_{0}$ is the discount rate for limit case of high values of $i_{1}$.

We observe that results for both versions of Modigliani-Miller theory are very closed: only from Tables it is seen that curve of dependence of WACC on leverage ratios of debt in "classical" ModiglianiMiller theory (curve WACC(2)) lies a little bit above all dependences of WACC on coverage ratio of debt in modified Modigliani-Miller theory. The WACC values are practically independent on $\mathrm{k}_{\mathrm{d}}$. As we will see below, the situation is quite difference in case of leverage ratios, where the influence of $k_{d}$ on dependences of WACC on leverage ratios is significant. 


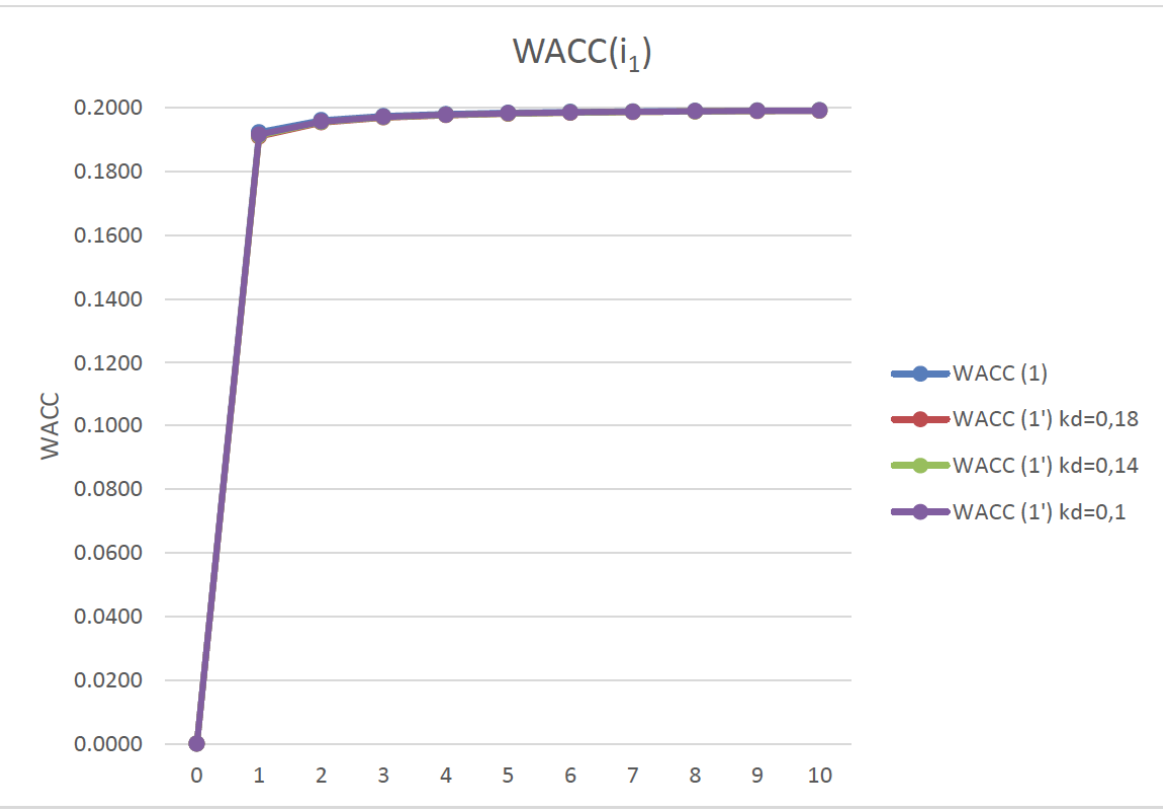

Figure 2: Dependence of WACC on coverage ratios of debt in "classical" Modigliani-Miller theory (curve WACC(1)) and in modified Modigliani-Miller theory (MMM theory) (curves WACC $(1 ')$ ) at $k d=0.1 ; 0.14 ; 0.18$.

\subsection{Leverage Ratios}

We will consider now the leverage ratios. Three kind of leverage ratios will be considered: leverage ratios of debt, leverage ratios of interest on the credit and leverage ratios of debt and interest on the credit.

\subsubsection{Leverage Ratios for Debt}

Here $l_{1}=D / C F$

As above for coverage ratios we use the modified Modigliani - Miller theorem for case with corporate taxes one has

$V_{L}=V_{0}+D t\left(1+k_{d}\right)$,

and dividing the both parts by $C F$, we derive the expression for $\operatorname{WACC}\left(I_{1}\right)$

$\frac{C F}{W A C C}=\frac{C F}{k_{0}}+D t\left(1+k_{d}\right)$

$\frac{1}{W A C C}=\frac{1}{k_{0}}+l_{1} t\left(1+k_{d}\right)$

$W A C C=\frac{k_{0}}{1+t l_{1} k_{0}\left(1+k_{d}\right)}$

This ratio $\left(I_{1}\right)$ can be used to assess of the following parameters used in rating, Debt/EBITDA and some others. We will use last formula to build a curve of dependence $\operatorname{WACC}\left(I_{1}\right)$.

\subsubsection{Leverage Ratios for Interest on Credit}

Here $l_{2}=k_{d} D / C F$

We use again Modified Modigliani - Miller theory (MMM theory) for case with corporate taxes

$V_{L}=V_{0}+D t\left(1+k_{d}\right)$,

and dividing the both parts by $C F / k_{d}$, we derive the expression for $W A C C\left(I_{2}\right)$

$\frac{C F}{W A C C}=\frac{C F}{k_{0}}+D t\left(1+k_{d}\right)$

$\frac{1}{W A C C}=\frac{1}{k_{0}}+\frac{l_{2} t\left(1+k_{d}\right)}{k_{d}}$

$W A C C=\frac{k_{0} k_{d}}{k_{d}+t l_{2} k_{0}\left(1+k_{d}\right)}$

This ratio $\left(I_{2}\right)$ can be used to assess of the following parameters used in rating, Interests/EBITDA and some others. We will use last formula to build a curve of dependence $\operatorname{WACC}\left(I_{2}\right)$.

\subsubsection{Leverage Ratios for Debt and Interest on Credit}

Here $l_{3}=D\left(1+k_{d}\right) / C F$

Using the Modified Modigliani - Miller theory (MMM theory) for case with corporate taxes 
$V_{L}=V_{0}+D t\left(1+k_{d}\right)$

and dividing the both parts by $C F /\left(1+k_{d}\right)$, we derive the expression for $W A C C\left(I_{3}\right)$

$\frac{C F}{W A C C}=\frac{C F}{k_{0}}+D t\left(1+k_{d}\right)$

$\frac{1}{W A C C}=\frac{1}{k_{0}}+l_{3} t$

$W A C C=\frac{k_{0}}{1+t l_{3} k_{0}}$

This ratio $\left(I_{3}\right)$ can be used to assess of the following parameters used in rating, Debt+interest / FFO, Debt+interest / EBIT, Debt+interest / EBITDA(R), and some others. We will use last formula to build a curve of dependence $\operatorname{WACC}\left(I_{3}\right)$.

3.4. Dependence of WACC on Leverage Ratios of Debt in "Classical" Modigliani-Miller Theory (MM Theory) and Modified Modigliani-Miller Theory (MMM Theory)

Below we study the dependences of WACC on leverage ratios of debt in "classical" Modigliani-Miller theory (MM theory) and modified Modigliani-Miller theory (MMM theory). We use Microsoft Excel, and the following parameters:

equity cost at $L=0 \mathrm{k} 0=0.2$; tax on profit rate $\mathrm{t}=0.2$; debt cost $k_{d}=0.1 ; 0.14 ; 0.18$; leverage ratios of debt $\mathrm{I}_{1}=0 ; 1 ; 2 ; 3 ; 4 ; 5 ; 6 ; 7 ; 8 ; 9 ; 10$.

Table 9: Dependence of WACC on Leverage Ratios of Debt in "Classical" Modigliani-Miller Theory

\begin{tabular}{|c|c|c|c|}
\hline ko & $\mathbf{I}_{1}$ & $\mathbf{t}$ & WACC \\
\hline \hline 0.2 & 0 & 0.2 & 0.2000 \\
\hline 0.2 & 1 & 0.2 & 0.1923 \\
\hline 0.2 & 2 & 0.2 & 0.1852 \\
\hline 0.2 & 3 & 0.2 & 0.1786 \\
\hline 0.2 & 4 & 0.2 & 0.1724 \\
\hline 0.2 & 5 & 0.2 & 0.1667 \\
\hline 0.2 & 6 & 0.2 & 0.1613 \\
\hline 0.2 & 7 & 0.2 & 0.1563 \\
\hline 0.2 & 8 & 0.2 & 0.1515 \\
\hline 0.2 & 9 & 0.2 & 0.1471 \\
\hline 0.2 & 10 & 0.2 & 0.1429 \\
\hline
\end{tabular}

Table 10: Dependence of WACC on Leverage Ratios of Debt in Modified Modigliani-Miller Theory (MMM Theory) at $\mathbf{k d}=\mathbf{0 . 1 8}$

\begin{tabular}{|c|c|c|c|c|}
\hline ko & $\mathbf{l}_{\mathbf{1}}$ & $\mathbf{t}$ & $\mathbf{k d}$ & WACC \\
\hline \hline 0.2 & 0 & 0.2 & 0.18 & 0.2000 \\
\hline 0.2 & 1 & 0.2 & 0.18 & 0.1910 \\
\hline 0.2 & 2 & 0.2 & 0.18 & 0.1827 \\
\hline 0.2 & 3 & 0.2 & 0.18 & 0.1752 \\
\hline 0.2 & 4 & 0.2 & 0.18 & 0.1682 \\
\hline 0.2 & 5 & 0.2 & 0.18 & 0.1618 \\
\hline 0.2 & 6 & 0.2 & 0.18 & 0.1559 \\
\hline 0.2 & 7 & 0.2 & 0.18 & 0.1503 \\
\hline 0.2 & 8 & 0.2 & 0.18 & 0.1452 \\
\hline 0.2 & 9 & 0.2 & 0.18 & 0.1404 \\
\hline 0.2 & 10 & 0.2 & 0.18 & 0.1359 \\
\hline
\end{tabular}

Table 11: Dependence of WACC on Leverage Ratios of Debt in Modified Modigliani-Miller Theory (MMM Theory) at $\mathrm{kd}=0.14$

\begin{tabular}{|c|c|c|c|c|}
\hline ko & $\mathbf{l}_{\mathbf{1}}$ & $\mathbf{t}$ & $\mathbf{k d}$ & WACC \\
\hline \hline 0.2 & 0 & 0.2 & 0.14 & 0.2000 \\
\hline 0.2 & 1 & 0.2 & 0.14 & 0.1913 \\
\hline 0.2 & 2 & 0.2 & 0.14 & 0.1833 \\
\hline 0.2 & 3 & 0.2 & 0.14 & 0.1759 \\
\hline 0.2 & 4 & 0.2 & 0.14 & 0.1691 \\
\hline 0.2 & 5 & 0.2 & 0.14 & 0.1629 \\
\hline 0.2 & 6 & 0.2 & 0.14 & 0.1570 \\
\hline 0.2 & 7 & 0.2 & 0.14 & 0.1516 \\
\hline 0.2 & 8 & 0.2 & 0.14 & 0.1465 \\
\hline 0.2 & 9 & 0.2 & 0.14 & 0.1418 \\
\hline 0.2 & 10 & 0.2 & 0.14 & 0.1374 \\
\hline
\end{tabular}

Table 12: Dependence of WACC on Leverage Ratios of Debt in Modified Modigliani-Miller Theory (MMM Theory) at kd=0.1

\begin{tabular}{|c|c|c|c|c|}
\hline ko & $\mathbf{I}_{\mathbf{1}}$ & $\mathbf{t}$ & $\mathbf{k d}$ & WACC \\
\hline \hline 0.2 & 0 & 0.2 & 0.1 & 0.2000 \\
\hline 0.2 & 1 & 0.2 & 0.1 & 0.1916 \\
\hline 0.2 & 2 & 0.2 & 0.1 & 0.1838 \\
\hline 0.2 & 3 & 0.2 & 0.1 & 0.1767 \\
\hline 0.2 & 4 & 0.2 & 0.1 & 0.1701 \\
\hline 0.2 & 5 & 0.2 & 0.1 & 0.1639 \\
\hline 0.2 & 6 & 0.2 & 0.1 & 0.1582 \\
\hline 0.2 & 7 & 0.2 & 0.1 & 0.1529 \\
\hline 0.2 & 8 & 0.2 & 0.1 & 0.1479 \\
\hline 0.2 & 9 & 0.2 & 0.1 & 0.1433 \\
\hline 0.2 & 10 & 0.2 & 0.1 & 0.1389 \\
\hline
\end{tabular}




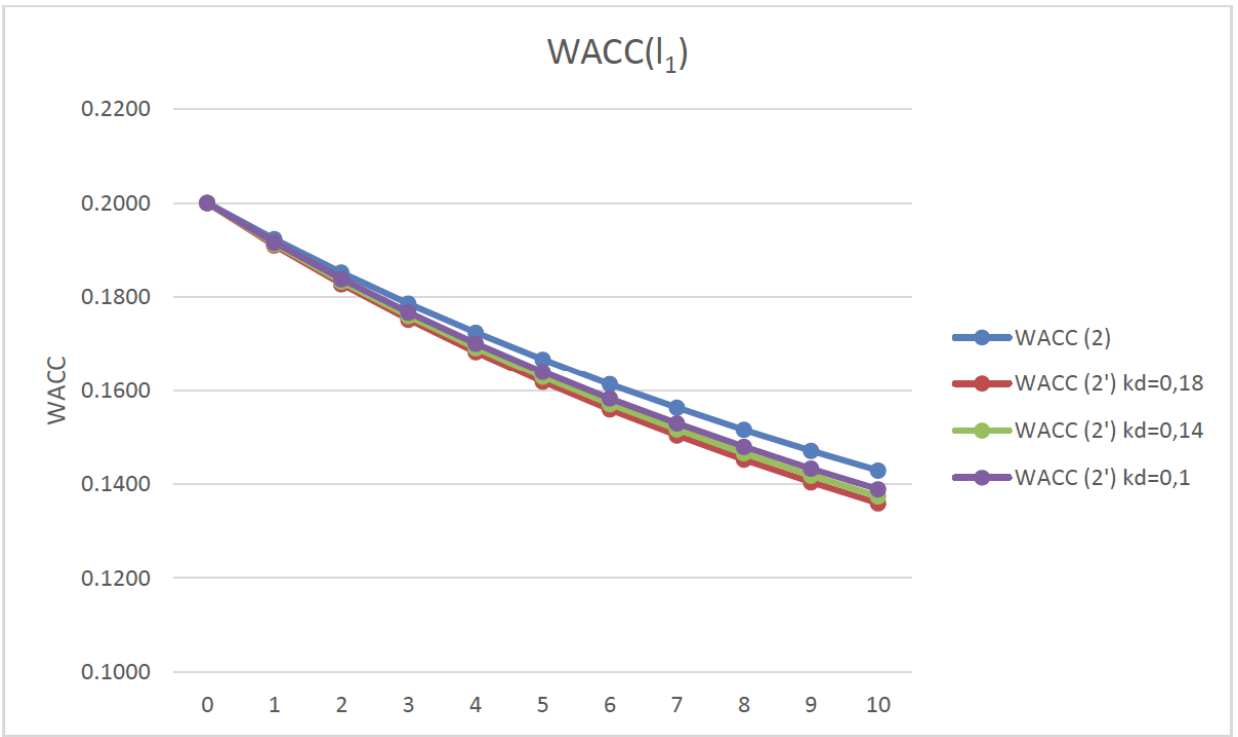

Figure 3: Dependence of WACC on leverage ratios of debt in "classical" Modigliani-Miller theory (curve WACC(2)) and in modified Modigliani-Miller theory (MMM theory) (curves WACC $(2 ')$ ) at $k d=0.1 ; 0.14 ; 0.18$.

Analysis of the dependences of company's weighted average cost of capital (WACC) on the leverage ratio on debt, $l_{1}$ shows the following: (see Figure 3) the weighted average cost of capital, WACC, decreases with leverage ratios for both versions of Modigliani-Miller theory: for "classical" ModiglianiMiller theory (MM theory) as well as for modified Modigliani-Miller theory (MMM theory). But we observe that curve of dependence of WACC on leverage ratios of debt in "classical" Modigliani-Miller theory (curve WACC(2)) lies above all dependences of WACC on leverage ratios of debt in modified Modigliani-Miller theory. The WACC values decreases with $k_{d}$. So we are observing the influence of $k_{d}$ on dependences of WACC on leverage ratios. This effect is absent in "classical" Modigliani-Miller theory. Thus the using of the modified Modigliani-Miller theory (MMM theory) leads to more correct valuation of the weighted average cost of capital (WACC), which plays the role of discount rate in financial flows discounting in rating methodologies. Obtaind results will help improve the existing rating methodologies.

\section{DISCUSSIONS}

In current paper we use the Modified Modigliani Miller theory (MMM theory) and apply it for rating methodologies needs. The financial "ratios" (main rating parameters) were introduced into MMM theory. The dependence of the weighted average cost of capital (WACC), which plays the role of discount rate in financial flows discounting in rating methodologies, on coverage and leverage ratios is analyzed. Obtaind results will help improve the existing rating methodologies.

The analysis of the dependence of company's weighted average cost of capital (WACC) on the coverage ratios on debt $i_{1}$ shows that WACC increases with coverage ratio of debt for both versions of Modigliani-Miller theory: for "classical" ModiglianiMiller theory (MM theory) as well as for modified Modigliani-Miller theory (MMM theory). WACC increases very rapidly at $L$ increases from $L=0$ to $L=1$ and then comes to saturation very fast (after $L=3$ WACC changes very weak). At saturation WACC reaches the value $k_{0}$ (equity cost at zero leverage level). This means that for high values of $i_{j}$ one can choose $k_{0}$ as a discount rate with a good accuracy. Thus the role of parameter $k_{0}$ increases drastically. The method of determination of parameter $k_{0}$ has been developed by Anastasiya Brusova (Brusova A (2011)). So, parameter $k_{0}$ is the discount rate for limit case of high values of $i_{1}$.

We observe that results for both versions of Modigliani-Miller theory are very closed: only from Tables it is seen that curve of dependence of WACC on leverage ratios of debt in "classical" ModiglianiMiller theory lies a little bit above all dependences of WACC on coverage ratio of debt in modified Modigliani-Miller theory. The WACC values are practically independent on $k_{d}$. The situation is quite different in case of leverage ratios, where the influence of $k_{d}$ on dependences of WACC on leverage ratios is significant. 
Analysis of the dependences of company's weighted average cost of capital (WACC) on the leverage ratio on debt, $l_{1}$ shows that WACC decreases with leverage ratios for both versions of ModiglianiMiller theory: for "classical" Modigliani-Miller theory (MM theory) as well as for modified Modigliani-Miller theory (MMM theory). We observe that curve of dependence of WACC on leverage ratios of debt in "classical" Modigliani-Miller theory lies above all dependences of WACC on leverage ratios of debt in modified Modigliani-Miller theory. The WACC values decreases with $k_{d}$. So we are observing the influence of $k_{d}$ on dependences of WACC on leverage ratios. This effect is absent in "classical" Modigliani-Miller theory. Thus the using of the modified Modigliani-Miller theory (MMM theory) leads to more correct valuation of the weighted average cost of capital (WACC), which plays the role of discount rate in financial flows discounting in rating methodologies. Obtained results will help improve the existing rating methodologies, which are used for valuation of the creditworthiness of companies.

Correct account of a method of tax on profit payments demonstrates that shortcomings of Modigliani - Miller theory are dipper, than everybody suggested: the underestimation of WACC really turns out to be bigger, as well as overestimation of the capitalization of the company. This means that systematic risks arising from the use of modified Modigliani - Miller theory (MMM theory) (which is more correct than "classical" one) in practice is higher than it was suggested by the "classical" version of this theory.

\section{DECLARATION OF INTEREST STATEMENT}

Recently we have modifided the theory of Nobel Prize winners Modigliani and Miller (MM theory), which is a perpetuity limit case of the general theory of capital cost and capital structure - Brusov-Filatova-Orekhova theory (BFO theory), into two ways: we apply it for rating methodologies needs and later we generalized it for the case of advance payments of tax on profit, which is widely used in practice (MMM theory). In current paper we use the Modified Modigliani - Miller theory (MMM theory) and apply it for rating methodologies needs. The financial "ratios" (main rating parameters) were introduced into MMM theory. The dependence of the weighted average cost of capital (WACC), which plays the role of discount rate in financial flows discounting in rating methodologies, on coverage and leverage ratios is analyzed. Obtained results will help improve the existing rating methodologies.

\section{ACKNOWLEDGEMENT}

We would like to thank Dr. Ekaterina Shirshova for useful discussions.

\section{REFERENCES}

P.N. Brusov, T.V. Filatova, N.P. Orekhova, V.L. Kulik, S.-I. Chang, Y.C.G. Lin (2020a), Modification of the Modigliani-Miller theory for the case of advance payments of tax on profit Journal of Reviews on Global Economics, v.9, p. 257-267. https://doi.org/10.6000/1929-7092.2020.09.25

Brusov Peter, Filatova Tatiana, Orekhova Natali (2020b) Ratings: Critical Analysis and New Approaches of Quantitative and Qualitative Methodology, monograph, Springer Nature Publishing, Switzerland.

Brusov P, Filatova T, Orehova N, Eskindarov M (2015), Modern corporate finance, investments and taxation, Springer International Publishing, Switzerland, 373 p. monograph. https://doi.org/10.1007/978-3-319-14732-1

Brusov P, Filatova T, Orehova N, Eskindarov M (2018a), Modern corporate finance, investments, taxation and ratings, Springer Nature Publishing, Switzerland, 571 p. monograph. https://doi.org/10.1007/978-3-319-99686-8

P.N. Brusov, T.V. Filatova, N.P. Orekhova, V.L. Kulik and I.Weil (2019a) Ratings of the investment projects of arbitrary durations: New methodology Journal of Reviews on Global Economics, v.8, p. 437-448.

https://doi.org/10.6000/1929-7092.2019.08.37

Peter Brusov, Tatiana Filatova \& Natali Orekhova (2014) Mechanism of formation of the company optimal capital structure, different from suggested by trade off theory, Cogent Economics \& Finance, v.2 issue 1: 946150, p.1-14, https://doi.org/10.1080/23322039.2014.946150

Peter Brusov, Tatiana Filatova, Natali Orehova \& Nastia Brusova (2011), Weighted average cost of capital in the theory of Modigliani-Miller, modified for a finite lifetime company Applied Financial Economics v.21, issue11, Pages 815-824. https://doi.org/10.1080/09603107.2010.537635

Brusov P (2018c) Editorial: Introduction on special issue on the Banking System and financial markets of Russia and other countries: Problems and prospects. Journal of Reviews on Global Economics , v.7, p. i-vi.

T.V. Filatova, P.N. Brusov, N.P. Orekhova and V.L. Kulik (2018d) Ratings of the long-term projects: New approach Journal of Reviews on Global Economics , v.7, P. 645-661, SCOPUS. https://doi.org/10.6000/1929-7092.2018.07.59

P.N. Brusov, T.V. Filatova, N.P. Orekhova and V.L. Kulik (2018e) Rating: New approach Journal of Reviews on Global Economics , v.7, Pages 37-62. https://doi.org/10.6000/1929-7092.2018.07.05

P.N. Brusov, T.V. Filatova, N.P. Orekhova and V.L. Kulik (2018f) A "golden age" of the companies: Conditions of its existence Journal of Reviews on Global Economics, v.7, p. 88-103. https://doi.org/10.6000/1929-7092.2018.07.07

P.N. Brusov, T.V. Filatova, N.P. Orekhova and V.L. Kulik (2018g) Rating methodology: New look and new horizons Journal of Reviews on Global Economics , v.7, p. 63-87. SCOPUS https://doi.org/10.6000/1929-7092.2018.07.06

P.N. Brusov, T.V. Filatova, N.P. Orekhova, V.L. Kulik and I.Weil (2018h) New meaningful effects in modern capital structure theory Journal of Reviews on Global Economics, v.7, p. 104122. https://doi.org/10.6000/1929-7092.2018.07.08

Brusov P (2018i) Editorial, Journal of Reviews on Global Economics , v.7, p. $i-v$, 
Peter Brusov, Tatiana Filatova, Natali Orekhova, Veniamin Kulik, Irwin Weil and Andrey Brailov (2018j) The impact of the central bank key rate and commercial banks credit rates on creating and maintaining of a favorable investment climate in the country Journal of Reviews on Global Economics, v.7, p.360-376.

https://doi.org/10.6000/1929-7092.2018.07.31

Brusov PN, Filatova TV, Orekhova NP, (2018k) Modern corporate finance and investments, monograph, Knorus publishing house, Moscow, $517 \mathrm{p}$. https://doi.org/10.1007/978-3-319-99686-8

Brusova A (2011) A Comparison of the three methods of estimation of weighted average cost of capital and equity cost of company. Financial analysis: problems and solutions 34 (76): 36-42
Filatova T, Orehova N, Brusova A (2008) Weighted average cost of capital in the theory of Modigliani-Miller, modified for a finite life-time company. Bull FU 48:68-77

T.V. Filatova, P.N. Brusov, N.P. Orekhova and V.L. Kulik (2018I) Ratings of the long-term projects: New approach Journal of Reviews on Global Economics , v.7, P. 645-661, SCOPUS. https://doi.org/10.6000/1929-7092.2018.07.59

Modigliani F, Miller M (1958) The cost of capital, corporate finance, and the theory of investment. Am Econ Rev 48:261-297

Modigliani F, Miller M (1963) Corporate income taxes and the cost of capital: a correction. Am Econ Rev 53:147-175

Modigliani F, Miller M (1966) Some estimates of the cost of capital to the electric utility industry 1954-1957. Am Econ Rev 56:333391.

Myers S (2001) Capital structure. J Econ Perspect 15(2):81-102. https://doi.org/10.1257/jep.15.2.81

Received on 16-07-2020

Accepted on 07-08-2020

Published on 03-09-2020

DOI: https://doi.org/10.6000/1929-7092.2020.09.28

(C) 2020 Brusov et al.; Licensee Lifescience Global.

This is an open access article licensed under the terms of the Creative Commons Attribution Non-Commercial License (http://creativecommons.org/licenses/by-nc/3.0/) which permits unrestricted, non-commercial use, distribution and reproduction in any medium, provided the work is properly cited. 